\title{
Ateísmo y descreimiento en la ciudad de San José (Costa Rica) a inicios del siglo XX. Una aproximación preliminar
}

\author{
IVÁN MOLINA JIMÉNEZ**
}

Resumen: En este artículo, se analiza en qué medida el ateísmo y el descreimiento se habían extendido en la ciudad de San José (Costa Rica) a inicios del siglo XX entre distintas categorías ocupacionales. Este fenómeno es considerado en el marco de la expansión de la alfabetización popular y de los esfuerzos de intelectuales liberales y radicales por secularizar la enseñanza, proceso fuertemente combatido por la Iglesia católica.

Abstract: This article analyzes to what extent atheism and disbelief were extended among the people from different occupations in the city of San José (Costa Rica) at the beginning of the twentieth century. This process was part of the expansion of popular literacy and the efforts of the liberal and radical intellectuals to secularize education, which was highly opposed by the Catholic Church.

Palabras clave: Ateísmo. Descreimiento. Religión católica. Costa Rica.

Keywords: Atheism. Disbelief. Catholic religion. Costa Rica.

El propósito de este artículo - producto de una investigación todavía en curso - es explorar el proceso de secularización en Costa Rica a inicios del siglo XX. La estrategia empleada para aproximarse a tal problemática consiste en confrontar dos fuentes de índole muy distinta, pero de origen urbano: la defensa de que era posible una moral profana, expuesta por el líder de un círculo de intelectuales radicales en el contexto de un conflicto creciente que tenía por epicentro el Liceo de Heredia; y las respuestas no convencionales a la pregunta sobre religión que figuran en el censo municipal de San José de 1904.

* La investigación de base para este artículo fue financiada por la Vicerrectoría de Investigación y se realizó en el Centro de Investigación en Identidad y Cultura Latinoamericanas (CIICLA) de la Universidad de Costa Rica.

* Catedrático de la Escuela de Historia e investigador del Centro de Investigación en Identidad y Cultura Latinoamericanas (CIICLA) de la Universidad de Costa Rica, San José, Costa Rica, América Central. E-mail: ivanm@fcs.ucr.ac.cr

Estudos Ibero-Americanos. PUCRS, v. XXX, n. 2, p. 39-48, dezembro 2004 
La conexión entre ambos documentos es posible porque, en la primera década del siglo XX, la expansión de la alfabetización popular facilitó que los discursos radicales, como esa defensa de una moral no religiosa, alcanzaran cada vez más, por vía de la prensa o del sistema educativo, a los sectores populares (lo cual, como se verá, dejó su impronta en el censo de 1904). El peligro de que esta tendencia se profundizara explica que la Iglesia, sus sacerdotes y sus feligreses se esforzaran sistemáticamente por combatirla: tal fue el eje del conflicto que se suscitó en torno a la enseñanza en el Liceo de Heredia.

\section{El apóstol de la moral independiente}

La designación en febrero de 1905 del poeta y masón, Roberto Brenes Mesén, como director del Liceo de Heredia - ubicado en una de las principales ciudades costarricenses -, fue el inicio de un prolongado conflicto cultural que, de lo local, pasó a lo nacional, y puso en serios aprietos a la administración del presidente Cleto González Víquez (1906-1910). El momento más crítico de esa confrontación, la más grave de su tipo ocurrida en Costa Rica durante el siglo XX, fue el año de 1907, cuando los católicos heredianos liderados por sus sacerdotes, con la excusa de que en el colegio indicado se enseñaba la teoría de la evolución, realizaron una intensa campaña para que los padres de familia no enviaran más a sus hijos e hijas a ese plantel, con el fin de forzar su cierre. ${ }^{1}$

La estrategia de los defensores de la fe, que impugnaban la secularización de la enseñanza que propició la reforma educativa de 1886 impulsada por los liberales, ${ }^{2}$ fue combatida tenazmente por un círculo de jóvenes intelectuales radicales - de orientación anarquista o socialista -, en el que destacaban, aparte del propio Brenes Mesén, los escritores Rubén Coto, José María Zeledón y Joaquín García Monge. ${ }^{3}$ El carácter nacional del enfrentamiento fue facilitado por la expansión de la alfabetización popular urbana y

1 Para un análisis detallado del conflicto, véase: MOLINA JIMÉNEZ, Iván. La ciudad de los monos. Roberto Brenes Mesén, los católicos heredianos y el conflicto cultural de 1907 en Costa Rica. Heredia: Editorial Universidad Nacional y Editorial de la Universidad de Costa Rica, 2001.

2 FISCHEL, Astrid. Consenso y represión. Una interpretación sociopolítica de la educación costarricense. San José: Editorial Costa Rica, 1987. Para una crítica de Fischel, véase: PALMER, Steven. Un paso adelante, dos atrás: una crítica de Consenso y represión de Astrid Fischel. In: Revista de Historia. San José, n. 18, julio-diciembre 1988, p. 227-242.

3 MORALES, Gerardo. Cultura oligárquica y nueva intelectualidad en Costa Rica: 18801914. Heredia: Editorial Universidad Nacional, 1993. 
rural (la proporción de personas de diez años y más que sabían leer y escribir superaba el 80 por ciento en las ciudades y el 50 por ciento en el campo en la década de 1900), ${ }^{4}$ proceso que explica que uno de los principales recursos al que apelaron los contendientes fuera la publicación de folletos, volantes y textos periodísticos.

La defensa de una moral profana que hizo Brenes Mesén contribuyó, sin duda, a que el conflicto se agudizara. ${ }^{5}$ El 3 de octubre de 1906, un grupo de señoras y señoritas de Heredia solicitó a la municipalidad de ese cantón que se abriera una clase de religión en el colegio. El municipio acogió tal petición y procedió a trasladarla al Consejo Superior del Liceo - encargado de autorizar todo cambio que se hiciera al plan de estudios -, el cual la rechazó, con base, entre otras razones, en los criterios expuestos por el director del plantel, a raíz de los cuales fue apodado por los católicos "el apóstol de la moral independiente". 6

El planteamiento de las señoras y señoritas de que la enseñanza religiosa era esencial para los jóvenes, fue considerado por Brenes Mesén como un prejuicio y un error; en sus propias palabras:

[...] cuando un hombre está convencido de que no hay un infierno ni un edén, y que no existe un Dios que premia y castiga al gusto de sus llamados ministros en la tierra, qué fuerza le impelerá á cumplir sus deberes de hombre? Ha sido, pues, preciso formar una moral fuera de la religión; de suerte que un individuo bien puede perder sus creencias religiosas sin llegar por eso a ser malvado... La religión no dirige la voluntad mejor que como lo hace el sentimiento de la responsabilidad personal, la confianza en nuestras propias fuerzas inspiradas por un generoso concepto del deber y el sentimiento de la solidaridad humana [...].7

4 MOLINA JIMÉNEZ, Iván; PALMER, Steven. Popular Literacy in a Tropical Democracy: Costa Rica, 1850-1950. In: Past and Present, n. 184, August, 2004, en prensa.

5 "De Heredia. Asunto palpitante. La municipalidad crea la clase de religión en el Liceo y el consejo de ese plantel la rechaza". In: Patria, n. 97, 28 de octubre de 1906, p. $1 ;$ n. 98,30 de octubre de 1906 , p. $1 ;$ n. 99,31 de octubre de 1906, p. 1 . El texto publicado en ese periódico incluye la petición de las señoras y señoritas heredianas, el acuerdo municipal que la apoya y los considerandos en que se basó el Consejo Superior del Liceo para rechazar lo solicitado.

6 LEÓN, Edwin, Una universidad en una ciudad de maestros (Heredia, Editorial Universidad Nacional, 1982), p. 84. MOLINA JIMÉNEZ, La ciudad de los monos... op. cit., p. 141-147.

7 "De Heredia. Asunto palpitante". Patria, n. 98, 30 de octubre de 1906, p. 1. 
El director del Liceo, en defensa de su posición, se permitió admitir que discrepaba incluso del presidente Cleto González Víquez, quien apenas unos meses atrás se había manifestado a favor de la enseñanza religiosa en las escuelas, un punto que las señoras y señoritas destacaron en su solicitud. La respuesta de Brenes Mesén enfatizó en la diferencia fundamental entre la educación primaria y la secundaria, ya que en esa época el acceso popular a la primera (especialmente a los grados básicos) era muy amplio, en tanto la matrícula colegial estaba dominada por los hijos e hijas de los sectores acomodados urbanos:

[...] los hombres que reciben una cultura superior pueden desprenderse de la moral religiosa; así se comprende en donde quiera y el actual Presidente de la República en su mensaje inaugural [del 8 de mayo de 1906] dice lo siguiente: 'La enseñanza religiosa que hoy se imparte en los establecimientos oficiales debe mantenerse y aún mejorarse en el sentido de que sea sincera y eficaz. Ello contribuirá a levantar la moral de nuestro pueblo, YA QUE NO ES DABLE ARRAIGAR LAS IDEAS DE SANA MORALIDAD ENTRE LAS GENTES DE POCA CULTURA SINO POR MEDIO DEL INSTRUMENTO RELIGIOSO' transcribo el párrafo anterior sin que esto signifique que acepto la totalidad de su contenido, para mostrar, una vez más, que toda persona que ha alcanzado cierto grado de cultura comprende y afirma la independencia de la moral, su divorcio de la religión. Ahora bien, no hay medio posible para equiparar la cultura que se imparte en el Liceo de Heredia y de las escuelas populares. Los fines son completamente distintos, su alcance es otro y en concordancia con todo ello, el plan de estudios debe ser diferente que el que se exige en una escuela...8

\section{Jerarquía familiar y religión declarada en el censo de 1904}

La exposición de Brenes Mesén es muy interesante porque permite aproximarse a los fundamentos ideológicos del proceso de secularización que la sociedad costarricense empezó a experimentar, de manera definida, a partir de la década de 1850. El desafío al catolicismo se expresó en el desarrollo, entre otras, de corrientes ateas, masónicas agnósticas, espiritistas, librepensadoras y teosóficas, todas muy poco exploradas, lamentablemente, en cuanto a su trasfondo social y cultural. ${ }^{9}$ Este vacío se explica,

8 "De Heredia. Asunto palpitante". Patria, n. 99, 31 de octubre de 1906, p. 1.

9 Para algunas excepciones, véase: OBREGÓN LORÍA, Rafael. Actividades masónicas en Centroamérica antes de 1865. San José: Imprenta Tormo, 1965; OBREGÓN LORÍA, Rafael; BOWDEN, George. La masonería en Costa Rica. San José: Trejos Hermanos, 1938. LÁSCARIS, Constantino. Desarrollo de las ideas filosóficas en Costa Rica. San José: Edi- 
en parte, por un problema de fuentes que es visible en el caso del censo de 1892, en el cual fueron consignados en la categoría de protestantes:

[...] todos los individuos que siendo bautizados, se desprende por las rarezas que han consignado en las cédulas de empadronamiento, que difieren de algunos principios de la Religión Católica. ${ }^{10}$

¿Cuáles eran esas "rarezas"? El censo de 1892 no las detalla, pero el efectuado en 1904 para la ciudad de San José sí permite aproximarse a tal fenómeno. El Cuadro 1 sintetiza lo expresado por 134 personas, de 15 años y más, ante la pregunta sobre cuál era su religión. ${ }^{11}$ Casi la mitad de las mujeres se declararon librepensadoras (14), seguidas en orden de importancia por las que contestaron que "ninguna" o que no tenían (9); entre los varones, en cambio, la primacía corresponde a los que afirmaron ser ateos o no tener religión o que respondieron "nada" y "sin religión" (47). ¿Fue el género, por tanto, un decisivo elemento diferenciador en cuanto a la radicalidad de la respuesta?

La información proporcionada por el Cuadro 1 obliga, en principio, a contestar afirmativamente la pregunta anterior; sin embargo, un examen del trasfondo familiar revela que todas las 30 mujeres (de las cuales 27 se ocupaban en oficios domésticos) ${ }^{12}$ declararon su religión según lo que contestó el jefe de la casa, con quien tenían lazos como esposas, hijas, hermanas, sobrinas, cuñadas, nueras, hijastras, concubinas o criadas, La única excepción parcial fue el caso del comerciante J. A. B., quien se calificó como librepensador, en tanto que una de sus sirvientas, de 63 años y de origen guatemalteco, se definió como "mazón".13

torial Costa Rica, 1965. MOLINA JIMÉNEZ, Iván; PALMER, Steven. La voluntad radiante. Cultura impresa, magia y medicina en Costa Rica (1897-1932). San José: Plumsock Mesoamerican Studies y Editorial Porvenir, 1996, p. 75-137. URBINA, Chester. Teosofía, intelectuales y sociedad en Costa Rica (1908-1929). In: Revista de Ciencias Sociales. San José, n. 88 , 2000, p. 139-144.

10 Oficial, Censo general de la República de Costa Rica levantado bajo la administración del licenciado don José J. Rodríguez el 18 de febrero de 1892 (San José, Tipografía Nacional, 1893), p. 1xxix.

11 Las 134 personas indicadas representan el 0,8 por ciento de los 16.483 josefinos de 15 años y más censados en 1904.

12 Las tres personas restantes declararon laborar como artista musical, maestra y costurera; de las 27 que afirmaron ocuparse en oficios domésticos, cinco eran criadas.

13 La utilización de iniciales cumple con el propósito de respetar la confidencialidad del censo. 


\section{Cuadro 1}

Respuestas dadas a la pregunta sobre cuál es su religión por 134 personas vecinas de San José de 15 años y más en el censo municipal de 1904, según sexo

\begin{tabular}{|lcc|lrc|}
\hline Respuesta & Varones & Mujeres & Respuesta & Varones & Mujeres \\
\hline Ateo & 4 & & Moralista & 1 \\
El deber & 2 & & Nada & 1 & \\
Espiritista & 3 & Ninguna & 35 & 8 \\
La libre religión del sentimiento 1 & 1 & & No creo ni en mí mismo & 1 & \\
Liberal & 4 & & No sectario & 1 & \\
Libertad de conciencia & 1 & 1 & No tiene & 1 & 1 \\
Librepensador & 34 & 14 & Racionalista & 3 & 2 \\
Masón & 2 & 1 & Respeta la conciencia ajena & 2 & 1 \\
Mi conciencia & 3 & 2 & Sin religión & 5 & \\
\hline Total & & & & 104 & 30 \\
\hline
\end{tabular}

1 Esta fue, por supuesto, la respuesta de un reconocido poeta de la época.

Fuente: Acuña, Víctor Hugo y Molina Jiménez, Iván, "Base de datos del censo municipal de San José de 1904” (San José, CIHAC, 1992-1997).

El peso de la jerarquía familiar, en términos de autoridad e identidad, en influir en la respuesta dada a la pregunta sobre religión fue muy inferior en cuanto a los varones: únicamente 20 de ellos contestaron igual que el cabeza del hogar, con el cual tenían vínculos como empleados, hermanos, hijos, hijastros y sobrinos. El problema planteado se puede examinar mejor a partir de lo siguiente: de los 104 hombres, 51 eran jefes, de los cuales apenas 22 parecen haber incidido en lo declarado por otros miembros de la casa, ya fuera la esposa o concubina (9 casos), esta última y otro pariente o dependiente (7 casos), $\mathrm{u}$ otros familiares o sirvientes (5 casos), aunque no por todos necesariamente.

Los 33 varones restantes, que no eran jefes ni contestaron igual que el cabeza de la casa, vivían uno en un cuartel, tres en un colegio, tres en hoteles o pensiones, y 26 pertenecían a 15 familias, encabezadas por una mujer protestante (1), por una católica (7) y por un varón de este último credo (7). Las diferencias religiosas, y en particular la apropiación de visiones de mundo contrarias al catolicismo prevaleciente, no fueron óbice para que creyentes y quienes no lo eran compartieran un mismo techo. El peso de la jerarquía familiar en cuanto a las declaraciones sobre religión, en el caso específico de esos hogares urbanos capitalinos - especial- 
mente en los siete que tenían una jefatura masculina - parece haber sido bastante limitado, un dato que invita a profundizar, en investigaciones posteriores, en el examen de la relación entre la tolerancia y el cosmopolitismo josefino.

La experiencia extrema con respecto a la aparente influencia del jefe en la declaración religiosa de sus parientes y dependientes fue la del comerciante Y. A., vecino del distrito El Carmen, donde se ubicaban algunas de las familias más prósperas de San José. El hogar que encabezaba estaba compuesto, además de él, por 16 personas: su esposa, cuatro hijastros, una hijastra, dos hijos, un sobrino, una sobrina, una nuera, una hermana, una nieta, dos empleados y una criada. Los 17 habitantes de esa casa figuran en el censo de 1904 como "librepensadores", en cuenta un niño de 9 y una niña de 6 meses, dos insólitos casos de tempranísimo descreimiento. ${ }^{14}$

\section{Diferenciación socio-ocupacional y secularización}

La tendencia de las mujeres a declarar según lo contestado por los jefes, y lo ocurrido en la familia de Y. A., resaltan la importancia de considerar, con sumo cuidado, los datos censales, y esto en un doble sentido. La apertura democrática que Costa Rica experimentó a partir de 1902, cuando el gobierno autoritario de Rafael Iglesias pactó con los sectores moderados de la oposición para dejar el Poder Ejecutivo, ${ }^{15}$ enfrentó a los políticos e intelectuales de la época, muchos de los cuales eran liberales, masones o radicales, con el desafío de competir por el apoyo de un electorado predominantemente rural y católico (en tal contexto se debe ubicar la declaración de mayo de 1906 del presidente González Víquez a favor de la enseñanza religiosa). ${ }^{16}$ El costo electoral y personal que podía tener toda expresión de irreligiosidad probablemente influyó en que un número de tales individuos, al preguntárseles su credo, optaran por adscribirse al catolicismo o por no contestar. ${ }^{17}$ La proporción de quienes declararon "rarezas" en 1904 está, por tanto, subestimada.

14 La persona que censó a esta familia registró equivocadamente que Y. A. era de religión católica, palabra que aparece tachada en la boleta original.

15 SALAZAR, Orlando. El apogeo de la república liberal en Costa Rica 1870-1914. San José: Editorial de la Universidad de Costa Rica, 1990, p. 200-211.

16 MOLINA JIMÉNEZ, Iván. Elecciones y democracia en Costa Rica, 1885-1913. In: European Review of Latin American and Caribbean Studies, Amsterdam, n. 70, April, 2001, p. 41-57; MOLINA JIMÉNE, La ciudad de los monos... op. cit., p. 140.

17 Esto se basa en un análisis de las respuestas dadas por algunos reconocidos liberales, masones y radicales en el censo de 1904. 
El otro problema consiste en que para explorar con más precisión el trasfondo social del proceso de secularización conviene descartar a las mujeres y a los varones que contestaron a la pregunta sobre religión igual que el jefe. La exclusión de unas y otros permite controlar el sesgo derivado de la influencia que podría tener la jerarquía familiar. El resultado de este ejercicio metodológico fue reducir el universo de análisis a 84 varones, cuyo perfil básico está sintetizado en el Cuadro 2. La mayoría (56 individuos o 66,7 por ciento), tenía 30 años o más, lo que significa que muchos de ellos vivieron el grave conflicto entre los liberales y la Iglesia católica durante las décadas de 1880 y 1890 , cuando fue secularizada la educación y se modificó el código civil para introducir el matrimonio y el divorcio civiles. ${ }^{18}$

El grueso de esos varones era casado o lo había estado (43 de 84 o 51,2 por ciento), por lo que no sorprende la importancia que tenían los jefes de familia: 60,7 por ciento; por otra parte, en cuanto a su origen, exactamente la mitad de todos esos individuos provenía de San José, muchos probablemente de la ciudad, aunque el censo no permite precisar este punto. Las otras provincias se encontraban escasamente representadas - especialmente Guanacaste y Puntarenas -, ya que apenas alcanzaban un quinto del total (20,2 por ciento); en contraste, los extranjeros, sí constituían una proporción significativa. La ventaja en este grupo le correspondía a los españoles (9) y a los oriundos del resto de Centroamérica y Panamá (8).

18 VARGAS, Claudio. El liberalismo, la Iglesia y el Estado en Costa Rica. San José: Alma Máter y Guayacán, 1991. RODRÍGUEZ SÁENZ, Eugenia. La aprobación del divorcio civil en Costa Rica en 1888. In: MOLINA JIMÉNEZ, Iván; ENRÍQUEZ SOLANO, Francisco (orgs.). Fin de siglo XIX e identidad nacional en México y Centroamérica. Alajuela: Museo Histórico Cultural Juan Santamaría, 2000, p. 143-176. Los extranjeros de 30 años y más incluidos en este grupo sumaban 20 personas, pero no se puede determinar desde cuándo vivían en Costa Rica. 


\section{Cuadro 2}

Perfil de 84 varones quienes declararon "rarezas" en el censo de 1904

\begin{tabular}{|c|c|c|c|c|c|c|c|c|c|}
\hline Edad & № & Estado Civil & № & Origen & $N^{o}$ & $\begin{array}{l}\text { Relación con } \\
\text { el jefe }\end{array}$ & $N^{o}$ & Ocupación & № \\
\hline $15-19$ & 2 & Casado & 38 & San José & 42 & Hijo & 14 & Abogado & 7 \\
\hline $20-24$ & 15 & Divorciado & 1 & Alajuela & 5 & Huésped & 4 & Agricultor & 3 \\
\hline $25-29$ & 11 & Soltero & 41 & Cartago & 3 & Jefe & 51 & Artesano & 30 \\
\hline $30-34$ & 14 & Viudo & 4 & Heredia & 6 & Otros $^{2}$ & 6 & Artista & 4 \\
\hline $35-39$ & 15 & & & Guanacaste & 2 & No aplica ${ }^{3}$ & 7 & Comerciante & 7 \\
\hline $40-44$ & 7 & & & Puntarenas & 1 & Yerno & 2 & Dependiente & 5 \\
\hline $45-49$ & 6 & & & Extranjeros $^{1}$ & 25 & & & Empleado público & 6 \\
\hline \multirow[t]{3}{*}{$50 y+$} & 14 & & & & & & & Maestro o profesor & 8 \\
\hline & & & & & & & & Tenedor de libros & 3 \\
\hline & & & & & & & & Otros $^{4}$ & 11 \\
\hline Total & 84 & Total & 84 & Total & 84 & Total & 84 & Total & 84 \\
\hline
\end{tabular}

1 La distribución por país era así: Argentina (1), Colombia (1), Cuba (1), El Salvador (1), España (9), Estados Unidos (3), Guatemala (2), Haití (1), Honduras (1), Nicaragua (2), Panamá (2), Suecia (1).

2 Las categorías incluidas aquí son: amigo (1), cuñado (1), esposo (1), nieto (1), padre (1) y sobrino (1).

3 Se trata de quienes vivían en un colegio, un cuartel y en hoteles o fondas.

4 Las ocupaciones son: farmacéutico (2), desconocido (1), escribiente (2), estudiante (1), jornalero (1), marinero (1), militar (2) y periodista (1).

Fuente: La misma del Cuadro 1.

La información más interesante que ofrece el Cuadro 2 se relaciona con la ocupación de los declarantes de "rarezas". Los profesionales (abogados y farmacéuticos) y los empleados de cuello blanco que laboraban en el sector público o privado (dependientes de comercio, empleados estatales, profesores, maestros, tenedores de libros, escribientes, artistas y periodistas) representaban el grupo más amplio: 38 de 84 (45,2 por ciento), seguidos de los artesanos (35,7 por ciento), categoría esta última que podía incluir desde patronos hasta asalariados, y en la que el oficio predominante era la zapatería ( 8 de 30 o 26,7 por ciento). ${ }^{19}$

19 La cultura radical de los zapateros, aunque para un período posterior, se analiza en: ACUÑA, Víctor Hugo; MOLINA JIMÉNEZ, Iván. Historia económica y social de Costa Rica (1750-1950). San José: Editorial Porvenir, 1991, p. 181-198. 
El trasfondo económico y social de las diez personas que se declararon agricultores y comerciantes era eventualmente muy diverso, ya que podía tratarse tanto de pequeños empresarios o de negociantes al por menor, como de miembros conspicuos de la burguesía josefina. Los oficios declarados por los restantes seis individuos son muy variados: jornalero (1), marinero (1), estudiante (1), militar (2) y desconocido (1). Los dos primeros son ubicables dentro de los sectores populares urbanos; sin embargo, la información disponible acerca de los cuatro últimos no permite determinar su posición dentro de la sociedad josefina.

\section{Epílogo}

El análisis precedente, pese a sus limitaciones, evidencia que la secularización social - y en particular, la apropiación de visiones de mundo que desafiaban el catolicismo predominante se había extendido de la cima a la base de la jerarquía social, y a lo largo de muy diversas categorías ocupacionales. La diferenciación en cuanto a riqueza, edad y oficio o profesión era, en cierto sentido, contrarrestada por un importante activo cultural: excepto dos panaderos, uno español y otro alajuelense de 60 y 40 años respectivamente, ${ }^{20}$ el resto de los varones sabía leer y escribir, un indicador del decisivo énfasis dado por el Estado liberal a la alfabetización popular a finales del siglo XIX.21

Los razonamientos expuestos por Roberto Brenes Mesén ante el Consejo Superior del Liceo de Heredia en octubre de 1906, lejos de constituir un discurso filosófico reservado a especialistas, podían tener eco, según se desprende de la evidencia examinada previamente, entre círculos sociales más amplios que los propiamente intelectuales. El peligro de que contribuyeran a extender el descreimiento entre individuos pertenecientes no solo a las capas medias, sino a los sectores populares, explica la firmeza con que fueron combatidos tales puntos de vista por los católicos, y especialmente por el clero.

20 Sobre los panaderos, véase: ROSABAL, Guillermo. El mundo del trabajo y la dinámica social en la producción de pan en Costa Rica. 1900-1950. San José, 1998. Tesis (Maestría en Historia) - Escuela de Historia - Universidad de Costa Rica.

21 MOLINA JIMÉNEZ, Iván; PALMER, Steven. Popular Literacy in a Tropical Democracy: Costa Rica, 1850-1950. In: Past and Present, n. 184, August, 2004, en prensa. 